\title{
Metabolic regulation of Irp gene expression in Escherichia coli K-12
}

\author{
C. F. Chen, J. Lan, M. Korovine, Z. Q. Shao, L. Tao, J. Zhang and \\ E. B. Newman
}

Author for correspondence: E. B. Newman. Tel: + 15148483410 . Fax: + 15148482881.

e-mail : neweb@vax2.concordia.ca

Biology Department

Concordia University, 1455

de Maisonneuve Ave.,

Montreal, Quebec, Canada H3G $1 \mathrm{M} 8$

\begin{abstract}
Expression of the Irp gene is regulated in part by the nutrients available to the cell, and is decreased in rich medium, in glucose minimal media enriched with amino acids, and in minimal medium with alternative carbon sources, such as acetate and succinate. When Lrp production is increased in a given medium, expression of its target genes is also increased. However, when the medium is changed from glucose to acetate, the response of the target genes is governed by many factors.
\end{abstract}

Keywords: Escherichia coli, leucine-responsive regulatory protein, regulation of $\operatorname{lr} p$ expression, metabolism

\section{INTRODUCTION}

The leucine-responsive regulatory protein $(\operatorname{Lrp})$ is a global regulator of Escherichia coli metabolism, and is particularly interesting because of the number and metabolic diversity of the reactions it affects (Newman et al., 1992; Newman \& Lin, 1995; Calvo \& Matthews, 1994). Lrp influences expression of genes whose products are involved in amino acid biosynthesis and degradation, nitrogen metabolism, carbohydrate degradation, synthesis of fimbriae, and transport. Regulation of some of these genes requires leucine as an effector, in which cases Lrp may be thought of as a regulator of variable gene expression like Crp (Lin et al., 1990). For these genes, leucine would act as a regulator just as cAMP does. In other cases, e.g. gltBDF (Ernsting et al., 1992) and $g c v$ (Lin et al., 1992), leucine has no effect in vivo, though Lrp is required for gene expression to the degree that the lrp mutant is metabolically deficient for both functions. For these genes, expression is possible as long as Lrp is made at normal levels. Lrp cannot be considered to regulate expression of these genes unless Lrp expression itself varies, or Lrp has effector(s) other than leucine (D'Ari et al., 1993).

Autogenous repression of $\operatorname{lr} p$ expression by Lrp itself has been previously described (Lin et al., 1992; Wang et al., 1994) and depends on Lrp binding to well-characterized sites upstream of the coding sequence (Wang et al., 1994). However, there is also a strong metabolic effect on Lrp expression which does not depend on the Lrp molecule as shown by the fact that a strain carrying

Abbreviation: Lrp, leucine-responsive regulatory protein. a lac $Z$ insert in the $\operatorname{lrp}$ gene produces about 1500 Miller units of $\beta$-galactosidase in glucose minimal medium (GMM) and only 115 Miller units in Luria broth (LB) (Lin et al., 1992).

In this paper, we consider some of the factors which may regulate expression of the $\operatorname{lrp}$ gene. We use a strain carrying a chromosomal $\operatorname{lrp}:$ : lac $Z$ fusion to define, in the absence of the Lrp gene product, which factors are responsible for this large reduction in $\operatorname{lrp}$ expression. We then show that a variation in Lrp concentration in vivo can influence expression of the target genes, other things being equal, and that there are other regulators of these target genes.

\section{METHODS}

Cultures and growth conditions. The plasmids and the strains used in this study, all derivatives of $E$. coli $\mathrm{K}-12$, are described in Table 1. Carbon sources were added at $0 \cdot 2 \%$ unless otherwise noted. Antibiotics were used as follows: $50 \mu \mathrm{g}$ kanamycin ${ }^{\prime} \mathrm{ml}^{-1}, \quad 30 \mu \mathrm{g}$ chloramphenicol $\mathrm{ml}^{-1}, \quad 100 \mu \mathrm{g}$ ampicillin $\mathrm{ml}^{-1}$ and $15 \mu \mathrm{g}$ tetracycline $\mathrm{ml}^{-1}$. Minimal medium and growth conditions were as described by Su \& Newman (1991).

Genetic methods. Plasmid isolations, DNA manipulations, transductions and transformations were performed as described by Maniatis et al. (1982) and Miller (1972).

Enzyme assays. $\beta$-Galactosidase was assayed in whole cells according to the method of Miller (1972) and its activity is expressed in Miller units.

Plasmid construction. To construct pMEW100 (pBAD221rp), we used the $\operatorname{lr} p$ gene which was previously cloned into pBAD18 with three mutations introduced in its upstream region (data not shown), forming pHE1. To create a 
Table 1. Plasmids and $E$. coli $\mathrm{K}-12$ strains used

\begin{tabular}{|c|c|c|}
\hline Strain/plasmid & Genotype and/or relevant characteristics & Source/reference \\
\hline \multicolumn{3}{|l|}{ Strains } \\
\hline CU1008 & $i l v A$ & L. S. Williams \\
\hline MEW1 & CU1008 slac & Lin et al. (1990) \\
\hline MEW 22 & MEW1 sdaA:: $\lambda$ placMu9 & Su et al. (1989) \\
\hline MEW26 & MEW1 $\operatorname{lrp}:: \operatorname{Tn} 10$ & Lin et al. $(1990)$ \\
\hline MEW45 & MEW1 lrp::lacZ & Lin et al. (1992) \\
\hline CP8 & MEW1 gltD: : lacZ & Tchetina \& Newman (1994) \\
\hline MEW 305 & serA : : $\mathrm{p} l a c M u 9$ & Z. Q. Shao \\
\hline MEW306 & MEW305 $\operatorname{lr} p:: \operatorname{Tn} 10$ & This work \\
\hline MEW307 & MEW45 ilv $A^{+}$ & This work \\
\hline CP67 & $g c v:: l a c Z$ & Lin et al. (1990) \\
\hline CV975 & $i l v I H:: l a c Z$ & Platko et al. (1990) \\
\hline \multicolumn{3}{|l|}{ Plasmids } \\
\hline pBAD22 & & Guzman et al. (1995) \\
\hline pLRN1 & pACYC84 $\operatorname{lr} p^{+}$ & Lin et al. (1992) \\
\hline pMC1871 & pBR322 lacZ ${ }^{+}$ & Lin et al. (1992) \\
\hline pMEW 100 & pBAD22 $\operatorname{lr} p^{+}$ & This work \\
\hline pMEW101 & pBAD22 lacZ ${ }^{+}$ & This work \\
\hline
\end{tabular}

pBAD: : lrp protein fusion on pBAD22, the coding region of the $\operatorname{lr} p$ gene was amplified from pHE1 using primers Lrp1, GGGGTACCCATGGTAGATAGCAAGA and Lrp2, GAAAAGCTTGTAACCTGGAG. The PCR product was cut with $K p n \mathrm{I}$ and HindIII and ligated to pBAD22 digested with the same restriction enzymes, resulting in pMEW100. This construction method results in the fusion of the complete coding region of the $l r p$ gene to the $3 \mathrm{rd}$ codon of the araB gene, under the control of the $a r a B A D$ promoter.

To construct a pBADlrp: : lacZ fusion, a $3 \mathrm{~kb}$ BamHI fragment carrying lacZ from pMC1871 was purified frorn a gel using a QIAGEN gel purification kit and ligated to pMEW 100 digested with $B g /$ III. The ligation mix was transformed into strain MEW1 and blue colonies were selected on LB plates

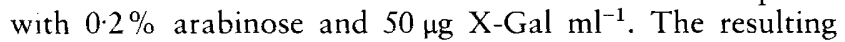
plasmid, pMEW101, carries the lac $Z$ gene fused in-frame to the 10th codon of $\operatorname{lrp}$ under the control of the $\operatorname{araBAD}$ promoter.

\section{RESULTS}

\section{Effect of amino acids on Irp expression}

In strain MEW45, the Lrp-deficient mutant used here, growth in GMM gave higher expression of $\operatorname{lrp}:$ : lacZ than we have seen in any conditions tested during exponential phase: 1445 units (Table 2). This was reduced more than 10 -fold by growth in LB with glucose, to 98 units, the lowest value we measured. The strong repressive effect of $\mathrm{LB}$ was almost equalled by adding Casamino acids ( $1 \%$ ) to GMM (170 vs 113 units; Table 2 ), suggesting that most of the effect of LB is due to amino acids (and not, for instance, to the absence of glucose).

Addition of various amino acids at $50 \mu \mathrm{g} \mathrm{ml}^{-1}$ reduced lrp expression, but two groups of amino acids produced a more significant reduction: those derived from oxaloacetate, and those derived from 2-oxoglutarate (Table 2). The diversity of amino acids decreasing $\operatorname{lr} p$ expression suggests that this may be a general metabolic effect related to general nitrogen and/or carbon nutrition rather than to any specific amino acid. Each of the oxaloacetate-derived amino acids (asparagine, aspartic acid, methionine, lysine and threonine) reduced expression from 1445 to between 1086 and 1193 units (Table 3). However threonine at $50 \mu \mathrm{g} \mathrm{ml}^{-1}$ had the most pronounced effect, reducing expression to about $50 \%$ (from 1445 to 772 units). A threefold increase in threonine to $150 \mu \mathrm{g} \mathrm{ml}^{-1}$ reduced expression only slightly more (to 725 units; data not shown). Adding methionine and lysine with the threonine did not substantially increase inhibition (data not shown). In the 2-oxoglutarate family, no particular amino acid seemed to predominate. Glutamine and glutamate together reduced expression to 1041 units, and arginine and proline to 870 . Biosynthesis of serine and leucine limit the growth of an lrp mutant, especially at high temperature (Ambartsoumian et al., 1994). We therefore assayed cultures grown with L-serine and L-leucine at $150 \mu \mathrm{g} \mathrm{ml}^{-1}$ each, obtaining a value of 1050 units (data not shown). When glycine was also added, a greater decrease was seen (645 units, Table 3 ).

Threonine also had pronounced and specific effects on the growth of the $\operatorname{lrp}$ mutant. Addition of threonine $\left(150 \mu \mathrm{g} \mathrm{ml}^{-1}\right)$ transiently inhibited growth of the $\operatorname{lrp}$ mutant. Subculture of cells grown in GMM into medium with $150 \mu \mathrm{g}$ threonine $\mathrm{ml}^{-1}$ inhibited growth for about $220 \mathrm{~min}$, after which the cells began to grow again at close to the same rate as cells growing without threonine. This inhibition was not seen in a similar experiment 
Table 2. Effect of nutrition on expression from Irp::/acz

Cells of strain MEW45 were grown at $37^{\circ} \mathrm{C}$ overnight in liquid media, subcultured and assayed after 3-4 h (mid-exponential phase) and several hours later (late-exponential/stationary phase).

Values given are the means \pm SD of at least three determinations. Isoleucine and valine were present in all media. LB, Luria broth. Glucose minimal medium (GMM) includes aspartic acid, asparagine, lysine, methionine and threonine at $50 \mu \mathrm{g} \mathrm{ml}^{-1}$. AA family: includes glutamic acid, glutamine, arginine and proline. 2-OG family: includes serine, glycine and cysteine. ND, Not determined.

\begin{tabular}{|lcc|}
\hline Growth medium & \multicolumn{2}{c|}{$\beta$-Galactosidase activity } \\
\cline { 2 - 3 } & & $\begin{array}{c}\text { Late-exponential/stationary } \\
\text { phase }\end{array}$ \\
\hline 1. LB & $113 \pm 14$ & $304 \pm 104$ \\
2. LB + glucose 0.2\% & $98 \pm 9$ & $\mathrm{ND}$ \\
3. GMM & $1445 \pm 262$ & $1775 \pm 488$ \\
4. GMM + CAA 1\% & $170 \pm 21$ & $296 \pm 83$ \\
5. GMM + AA family & $303 \pm 33$ & $835 \pm 197$ \\
6. GMM +2-OG family & $430 \pm 43$ & $842 \pm 210$ \\
\hline
\end{tabular}

Table 3. Effects of amino acids on expression from Irp::lacZ

Cells of strain MEW45 were grown at $37^{\circ} \mathrm{C}$ overnight in liquid GMM with various supplements, each at $50 \mu \mathrm{g} \mathrm{ml}^{-1}$, subcultured in the same medium and assayed after $3-4 \mathrm{~h}$. All values are means \pm SD of at least three determinations. Valine and isoleucine were added to all cultures.

\begin{tabular}{|lc|}
\hline Supplement & $\boldsymbol{\beta}$-Galactosidase activity \\
\hline Glutamine, glutamate & $1041 \pm 59$ \\
Arginine, proline & $870 \pm 57$ \\
Asparagine, aspartate & $1132 \pm 32$ \\
Methionine & $1086 \pm 26$ \\
Lysine & $1193 \pm 67$ \\
Threonine & $772 \pm 93$ \\
Serine, glycine, cysteine & $645 \pm 76$ \\
\hline
\end{tabular}

with the parent strain, MEW1. Since one of the two aspartokinase-homoserine dehydrogenase enzymes, the thrA gene product, is inhibited by threonine, the transient stoppage in growth might be due to a requirement for Lrp in transcription of met $L$, the gene encoding the second enzyme. Adding threonine to an Lrp-deficient strain would then block methionine biosynthesis. Dependence on Lrp for activation of the gene encoding the first step in biosynthesis is also seen for leucine and serine (Newman \& Lin, 1995; Calvo \& Matthews, 1994).

\section{Effect of carbon and energy source on Irp expression}

Expression of $\operatorname{lrp}$ also varied a great deal in cultures grown with different carbon sources. Expression was most severely reduced (to about $40 \%$ of the glucosegrown level) in cells grown with succinate and acetate
Table 4. Effect of carbon source on expression from Irp::lacZ

MEW45 cells were grown at $37^{\circ} \mathrm{C}$ overnight in liquid minimal medium with various carbon sources, subcultured in the same medium and assayed after $3-4 \mathrm{~h}$. All values are means $\pm \mathrm{SD}$ of at least three determinations.

\begin{tabular}{|lc|}
\hline Carbon source & $\boldsymbol{\beta}$-Galactosidase activity \\
\hline Glucose & $1445 \pm 262$ \\
Rhamnose & $1080 \pm 194$ \\
Arabinose & $1173 \pm 84$ \\
Glycerol & $1094 \pm 26$ \\
Pyruvate & $961 \pm 42$ \\
Acetate & $558 \pm 34$ \\
Succinate & $584 \pm 45$ \\
\hline
\end{tabular}

(Table 4). Expression was much less reduced in cells grown with glycerol or pyruvate, and with a variety of sugars (maltose, rhamnose and arabinose). Levels were higher in glucose-grown cultures than in any other conditions tested. However, addition of glucose to rich media had little effect, repressing very slightly (Table 2 ).

\section{Variation in Irp expression during growth}

All values quoted so far were taken from overnight batch cultures subcultured for several hours and assayed in the exponential phase. These cultures were also assayed several hours later, i.e. in late-exponential or early-stationary phase, and in every case showed a higher level later (Table 2). To see if this effect was due to the cultures becoming anaerobic, we transferred exponential-phase cells to GMM-filled containers and assayed $\operatorname{lr} p$ after $1.5 \mathrm{~h}$. No increase was seen (data not shown). 


\section{Effect of Lrp on Irp expression}

The experiments quoted above describe the behaviour of the cell in the absence of autogenous regulation. We also tested $\operatorname{lr} p:$ : lacZ expression in strain MEW45 (pLRN1) carrying a functional $\operatorname{lr} p$ gene on a multicopy plasmid. Cells with several copies of a functional $\operatorname{lrp}$ gene produced only $244 \pm 40$ units of $\beta$-galactosidase in CiMM, whereas cells grown in succinate minimal medium or in LB produced considerably less $(182 \pm 13$ and $122 \pm 11$ units, respectively). It seems that expression of the $\operatorname{lr} p$ gene can be strongly repressed either by nutritional changes or by overproduction of Lrp on a multicopy plasmid.

\section{Variation in serA expression as influenced by Lrp production}

The preceding experiments show that $\operatorname{lr} p$ expression is altered by a number of factors. This could be of physiological importance only if variations in $\operatorname{lrp}$ expression within a physiological range influenced the expression of genes regulated by Lrp. We show that variations in Lrp are in fact closely reflected in serA expression by measuring $\operatorname{ser} A$ expression in a cell carrying a chromosomal $\operatorname{ser} A:$ : lacZ fusion and a plasmid carrying a functional $l r p$ gene under the control of the arabinose promoter. We grew strain MEW306 transformed with $\mathrm{pBADl} r \mathrm{p}^{+}$in glycerol minimal medium with the arabinose concentrations noted, and found that lacZ expression from ser $A$ : : lacZ followed the arabinose concentration from 0 to between 10 and $20 \mu \mathrm{g}$ arabinose $\mathrm{ml}^{-1}$ (Fig. $1 \mathrm{a}$, curve 1). Using strain MEW26 $\operatorname{lrp}:: \operatorname{Tn} 10$ pBADlrp::lacZ, we showed that lac $Z$ expression from $\operatorname{lrp}:$ : lac $Z$ responds similarly over the same range (Fig. $1 \mathrm{a}$, curve 2 ). These data are replotted in Fig. 1 (b) as a percentage of the usual wildtype expression from $\operatorname{ser} A:$ : lacZ in glycerol minimal medium ( 850 units; data not shown). This figure shows that $20 \mu \mathrm{g}$ arabinose $\mathrm{ml}^{-1}$ is enough to achieve expression at a level close to that of a normal Lrpproducing cell. In Fig. 1(c), an estimate of serA expression as a function of Lrp is obtained by plotting the curves in Fig. 1 (a) against each other. This indicates that at levels of Lrp up to about 600 units $\beta$-galactosidase, serA expression varies linearly with Lrp.

\section{Effect of growth conditions on expression of Lrp- regulated genes}

It is clear that variations in Lrp production may be reflected in target gene expression, all other things being equal. To determine whether this is true in usual growth conditions where all things are not equal, we compared the expression of target genes in GMM with that seen in LB and in succinate minimal medium where the level of lrp expression is considerably lower (Table 5).

If Lrp concentration were the major determinant of expression of the genes whose expression it is known to affect, one would expect the level of these to vary in a systematic manner in these media. We tested expression
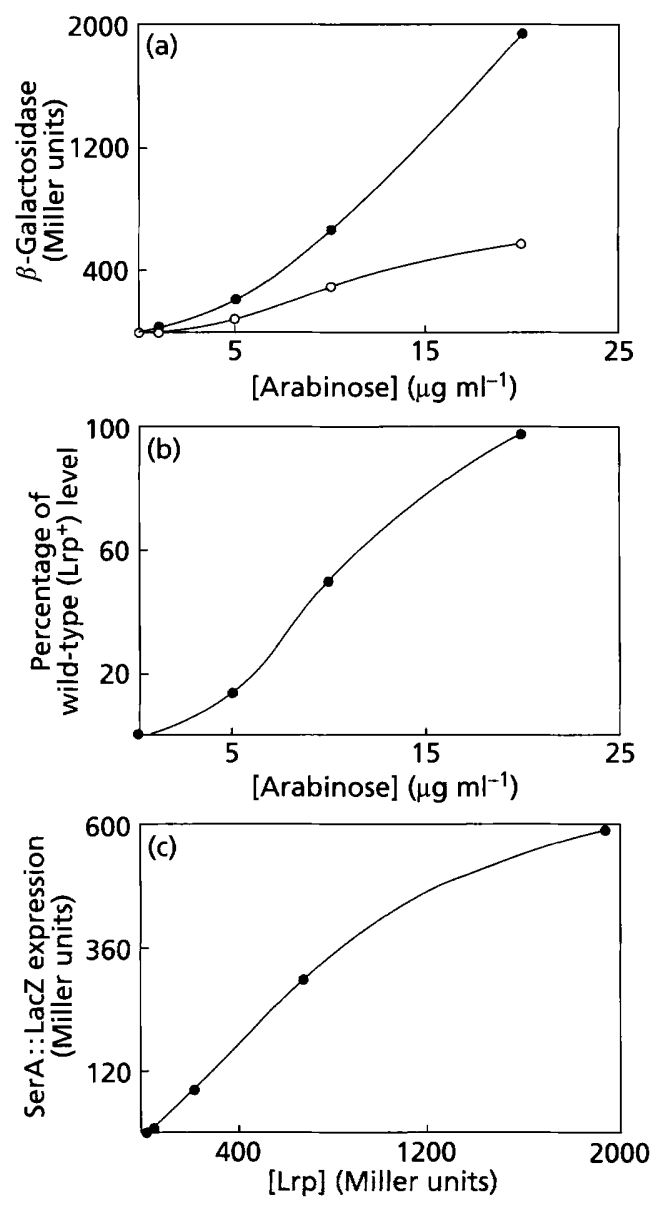

Fig. 1. Expression of Irp under the control of the arabinose promoter PBAD. (a) Cells of strain MEW26 Irp::Tn10 pMEW101 (pBADlacZ), curve 1 (0), and strain MEW306 Irp::Tn10 serA::lacZ pMEW100 (pBAD/rp), curve $2(0)$, were grown overnight in glycerol minimal medium with various arabinose concentrations, subcultured in the same medium, and assayed for $\beta$-galactosidase in mid-exponential phase. L-Serine $(500 \mu \mathrm{g}$ $\mathrm{ml}^{-1}$ ) was added to both cultures because serine is required by MEW306. The basal expression of serA::lacZ from a second Lrpindependent promoter (253 units) is subtracted from all values in curve 2. (b) Replotting of (a) curve 1 as a percentage of the serA::lacZ expression seen in strain MEW305 grown in glycerol minimal medium with serine $500 \mu \mathrm{g} \mathrm{ml}^{-1}$ (850 units from which the same 253 units were subtracted). (c) Replotting of (a): curve 2 is plotted against curve 1, showing serA expression as a function of Lrp concentration.

of five genes, $g c v$, ser $A, i l v I H, g l t D$ and $s d a A$, carrying lac $Z$ translational fusions and found that expression of these genes varies in a much more complex way than does $\operatorname{lrp}$ expression (Table 5). It is obvious that while variations in Lrp production can affect target gene expression, Lrp is only one of the factors that determines the rate of expression of its target genes.

\section{DISCUSSION}

In this paper, we demonstrate a number of metabolic factors influencing the expression of the $\operatorname{lr} p$ gene in $E$. coli $\mathrm{K}-12$. Irp expression varied according to both carbon 
Table 5. Effect of growth medium on expression of Lrpregulated genes

For this experiment strains were grown at $37^{\circ} \mathrm{C}$ overnight in liquid media as stated, subcultured in the same medium, and assayed after $4 \mathrm{~h}$. All values are means \pm SD of at least two determinations and cited as in Table 2. SMM, succinate minimal medium.

\begin{tabular}{|lccc|}
\hline Strain & \multicolumn{3}{c|}{$\beta$-Galactosidase activity in } \\
\cline { 2 - 4 } & GMM & LB & SMM \\
\hline CP8 & $347 \pm 60$ & $20 \pm 2$ & $146 \pm 11$ \\
MEW305 & $472 \pm 31$ & $189 \pm 11$ & $385 \pm 16$ \\
CP67 & $248 \pm 16$ & $166 \pm 12$ & $1421 \pm 61$ \\
MEW22 & $58 \pm 4$ & $156 \pm 10$ & $45 \pm 3$ \\
CV975 & $255 \pm 30$ & $7 \pm 1$ & $199 \pm 29$ \\
\hline
\end{tabular}

and nitrogen metabolism. Expression in GMM decreased with the addition of almost any amino acid, particularly those like threonine, which were derived from tricarboxylic acid (TCA) cycle intermediates. Indeed the only amino acids without much effect were leucine and the aromatic amino acids. Expression was not affected by growth on hexoses, glycerol or pyruvate, but was greatly reduced during growth on acetate and succinate. It seems that expression of $\operatorname{lr} p$ is correlated in some way with the use of the TCA cycle. However the physiological meaning of this correlation is unclear. The mechanism for this metabolic regulation of $\operatorname{lrp}$ expression is not known. In any case, it does not involve the $\operatorname{lr} p$ gene product, since these studies were done in an Lrp-deficient strain. The presence of Lrp decreased expression levels in all cases, but metabolic regulation could be shown even when Lrp was present. Autogenous regulation involves binding of Lrp to a site between 32 and 80 bp upstream of the transcription start site of the $\operatorname{lrp}$ gene, as indicated by gel-mobility shifts, DNA footprinting, and mutation and deletion studies (Wang et al., 1994). In the metabolic regulation system, neither a signalling molecule(s) nor its effector has been identified.

\section{Effects of variation in Lrp concentration on gene expression}

The total absence of Lrp, as in the $\operatorname{lrp}$ mutant, abolishes expression of several genes, including $g c v$ and gltD, making an $\operatorname{lr} p$ mutant physiologically deficient in these functions. However a quantitative relationship between Lrp production in vivo and target gene expression has not been shown. We show here that gradual variation in Lrp concentration directly affects ser $A$ expression, as judged by the effect of variations in induction of $\operatorname{lrp}$ on a variable expression vector such that the Lrp concentration varied with the arabinose concentration provided to the cells. In the experiments shown in Fig. 1, ser A : lac Z expression was about 250 units without Lrp, and reached 900 units with $50 \mu \mathrm{g}$ arabinose $\mathrm{ml}^{-1}$. We conclude that $\operatorname{ser} A:$ : lac $Z$ expression is directly responsive to variations in Lrp concentration within a physiological range. In similar experiments, lac $Z$ fusions to gcv, gltD and $s d a A$ behaved similarly (data not shown).

In the preceding experiments, Lrp concentration was the only factor varied. Target gene expression was also studied in two conditions in which lrp expression was decreased, but many other metabolic conditions varied: in $\mathrm{LB}$, a rich medium containing a variety of biosynthetic precursors, and in a minimal medium with succinate as carbon source, where the cell relies on gluconeogenesis.

In these experiments, a direct correlation between Lrp concentration and target gene expression could not be seen. This is hardly surprising, since these media vary in so many factors other than Lrp concentration, and each of the target genes has multiple promoters and may respond to several regulators.

For several genes, expression depends absolutely on the presence of Lrp. Above a certain threshold level, the amount of Lrp may not influence expression much, especially for those promoters with high affinity for Lrp. For these genes, Lrp is needed to set the stage, and may thus be involved in determining chromosome structure as suggested earlier by D'Ari et al. (1993). A variety of other factors from end-product inhibition to other general transcription factors may be involved in the actual setting of the transcription rate of the target genes.

\section{REFERENCES}

Ambartsoumian, G., D'Ari, R., Lin, R. T. \& Newman, E. B. (1994). Altered amino acid metabolism in lrp mutants of Escherichia coli K12 and their derivatives. Microbiology 140, 1737-1744.

Calvo, J. M. \& Matthews, R. G. (1994). Leucine-responsive regulatory protein - a global regulator of metabolism in Escherichia coli. Microbiol Rev 58, 466-498.

D'Ari, R., Lin, R. T. \& Newman, E. B. (1993). The leucine-responsive regulatory protein: more than a regulator? Trends Biochem Sci 18, 260-263.

Ernsting, B. R., Atkinson, M. R., Ninfa, A. J. \& Matthews, R. G. (1992). Characterization of the regulon controlled by the leucine responsive regulatory protein in Escherichia coli. J Bacteriol 174, 1109-1118.

Guzman, L. M., Belin, D., Carson, M. J. \& Beckwith, J. (1995). Tight regulation, modulation, and high-level expression by vectors containing the arabinose PBAD promoter. I Bacteriol 177 , 4121-4130.

Lin, R., D'Ari, R. \& Newman, E. B. (1990). The leucine regulon of Escherichia coli: a mutation in $r b l A$ alters expression of L-leucinedependent metabolic operons. J Bacteriol 172, 4529-4535.

Lin, R., D'Ari, R. \& Newman, E. B. (1992). $\lambda$ placMu insertions in genes of the leucine regulon: extension of the regulon to genes not regulated by leucine. J Bacteriol 174, 1948-1955.

Maniatis, T., Fritsch, E. F. \& Sambrook, J. (1982). Molecular Cloning : a Laboratory Manual. Cold Spring Harbor, NY : Cold Spring Harbor Laboratory.

Miller, J.H. (1972). Experiments in Molecular Genetics. Cold Spring Harbor, NY : Cold Spring Harbor Laboratory. 
Newman, E. B. \& Lin, R. T. (1995). Leucine-responsive regulatory protein, a global regulator of gene expression in E. coli. Annu Rev Microbiol 49, 747-775.

Newman, E. B., D'Ari, R. \& Lin, R. T. (1992). The leucine-Lrp regulon in E. coli: a global response in search of a raison d'etre. Cell 68, 617-619.

Platko, J. V., Willins, D. A. \& Calvo, J. M. (1990). The ilvIH operon of Escherichia coli is positively regulated. J Bacteriol 172, 4563-4570.

Su, H. \& Newman, E. B. (1991). A novel L-serine deaminase activity in Escherichia coli K-12. J Bacteriol 173, 2473-2480.

Su, H., Lang, B. F. \& Newman, E. B. (1989). L-Serine degradation in
Escherichia coli $\mathrm{K}-12$. Cloning and sequencing of the sdaA gene. $J$ Bacteriol 171, 5095-5102.

Tchetina, E. \& Newman, E. B. (1994). Identification of Lrpregulated genes by inverse PCR and sequencing: regulation of two $\mathrm{mal}$ operons in $E$. coli by leucine-responsive regulatory protein. J Bacteriol 177, 2679-2683.

Wang, Q., Wu, J., Friedberg, D., Platko, J. \& Calvo, J. M. (1994). Regulation of the Escherichia coli lrp gene. J Bacteriol 176, 1831-1839.

Received 13 September 1996; revised 20 January 1997; accepted 12 February 1997. 